\title{
PERSEPSI IBU TENTANG PEMBERIAN OBAT FILARIASIS UNTUK PENCEGAHAN ELEPHANTIASIS PADA BALITA DI DESA JONO TAWANGHARJO GROBOGAN
}

\author{
Emma Nur Chayati ${ }^{1}$, DitaWasthu $\mathrm{P}^{2}$ \\ ${ }^{1,2}$ Prodi DIV Kebidanan, STIKes Karya Husada Semarang \\ Email: wprasida@yahoo.co.id
}

\begin{abstract}
ABSTRAK
Latar Belakang:Penyakit filariasis sampai saat ini masih menjadi masalah bagi kesehatan masyarakat. Data Dinas Kesehatan Kabupaten Grobogan Tahun 2015 angka kejadian penderita mencapai 11 kasus, termasuk data yang ada di Tawangharjo yaitu ada 3 kasus, yang terdapat di Desa Jono. Pada pemberian obat pencegahan filariasis di desa Jono yaitu mencapai 682 jiwa kecuali anak dibawah 2 tahun, ibu hamil, penderita penyakit berat dan usia lebih dari 70 tahun. Menurut data yang bersumber dari Direktorat Jenderal Pengendalian Penyakit dan Penyehatan Lingkungan Departemen Republik Indonesia, saat ini Indonesia ada 302 kabupaten/kota yang endemis filariasis serta Peraturan Menteri Kesehatan Republik Indonesia Nomor 94 Tahun 2014 Tentang Penanggulangan Filariasis yaitu Pemutusan rantai penularan sebagaimana yang dimaksud dilaksanakan paling sedikit melalui Pemberian Obat Pencegahan Secara Masal (POPM) Filariasis pada wilayah endemis Filariasis dan upaya perlindungan dari gigitan nyamuk. Tujuan penelitian: untuk melihat implementasi pelaksanaan pemberian obat massal pencegahan filariasis di kabupaten Grobogan tahun 2015. Metode Penelitian: Penelitian ini menggunakan metode kualitatif dengan desain ,melalui wawancara terarah. Subyek penelitian adalah ibu-ibu yang mempunyai anak balita (2-5 tahun) yang mendapatkan pengobatan massal. Hasil penelitian: Pemberian obat secara massal untuk pencegahan filariasis pada balita (2-5 tahun) sangat diperlukan dan didukung oleh masyarakat, karena pengobatan massal ini akan berpengaruh terhadap rantai penularan penyakit filariasis yang mengakibatkan penyakit menahun dan cacat permanen pada penderitanya apabila tidak ditangani secara cepat. Tenaga kesehatan diharapkan meningkatkan sosialisasi tentang cara pencegahan filariasis dan memberikan pengobatan massal filariasis secara berkelanjutan untuk memutus rantai penyakit filariasis.
\end{abstract}

Kata kunci : Persepsi; Pencegahan; Obat Filariasis

\section{MOTHER'S PERCEPTION ABOUT DRUG FOR PREVENTION ELEPHANTIASIS FILARIASIS IN TODDLERS IN TAWANGHARJO GROBOGAN}

\begin{abstract}
Background: Filariasis is still a problem for public health. Data health departementGrobogan 2015 the incidence of patients reached 11 cases, including data on the Tawangharjo namely 3 cases, contained in Jono village. Filariasis prevention of drug administration in Jono village, reaching 628 inhabitants except children under 2 years old, woman pregnant, patients with severe disease and the elderly over 70 years. According to data from the Directorate General of Disease Control and Environmental Health Department of the Republic of Indonesia, Indonesia there are 302 districts / cities are endemic filariasis as well as the Regulation of the Minister of Health of the Republic of Indonesia Number 94 Year 2014 About the Countermeasures Filariasisie Termination of the chain of transmission within the meaning carried out at least through Prevention off Mass Drug Administration (POPM) Filariasis in endemic areas of filariasis and protective measures against mosquito bites. Purpose: The purpose of this study is to see the implementation of the implementation of preventive filariasis mass drug administration in Grobogan 2015. Method: This study used qualitative methods to design, through targeted interviews. Subjects were mothers who have young children (2-5 years) who received mass treatment. Result: The results of this study indicate that mass drug administration for filariasis prevention in infants (2-5 years) is required and supported by the community, because this mass treatment would affect the chain of transmission of filariasis disease resulting in chronic diseases and permanent physical disabilities of patients if not treated rapidly.Health workers are expected to increase the socialization and give filariasis mass treatment on an ongoing basis to break the chain of filariasis.
\end{abstract}




\section{Pendahuluan}

Infeksi cacing merupakan salah satu penyakit yang paling umum tersebar dan menjangkit banyak manusia di seluruh dunia. Pada umumnya cacing jarang menimbulkan penyakit yang serius tetapi dapat mengakibatkan gangguan kesehatan kronis yang berhubungan dengan faktor ekonomis. Salah satu dari infeksi cacing adalah cacing filaria yang menimbulkan pembesaran kaki yang disebut elephantiasis (kaki gajah), pembesaran lengan dan alat kelamin. Dan akan tampak pada ukuran kaki yang membesar dengan ukuran diameter hingga $30 \mathrm{~cm}$, pembesaran lengan ataupun alat kelamin. (Akhsin Zulkoni, 2010 : 71)

Penyakit filariasis merupakan penyakit parasit yang penyebarannya tidak merata, melainkan terkonsentrasi di beberapa kantong-kantong wilayah tertentu. Dataran pulau Sumatera serta sebagian besar wilayah Jawa dan Bali menjadi kawasan yang dari tahun ke tahun langganan terinfeksi penyakit ini.

Filariasis atau penyakit kaki gajah adalah penyakit menular yang disebabkan oleh cacing filarial yang ditularkan melalui berbagai jenis nyamuk. Penyakit ini bersifat menaun (kronis) dan apabila tidak mendapatkan pengobatan akan mengakibatkan cacat menetap berupa pembesaran kaki, alat kelamin baik perempuan maupun laki-laki (Padila, 2013 : 411).

Lima tahun terakhir, sejak tahun 2008 sampai dengan tahun 2014 kasusfilariasis di Jawa Tengah selalu ditemukan dan secara kumulatif mengalamipertambahan jumlah kasus filariasis kronis.Disamping terjadi peningkatan jumlah kasus filariasis kronis, jugabertambahnya Kabupaten/Kota yang sebelumnya tidak pernah melaporkanadanya penderita filariasis kronis. Sampai dengan tahun 2014 sudah 34Kabupaten/Kota yang melaporkan ditemukan penderita filariasis kronis atau menahun (Profil Kesehatan Dinkes Jateng, 2014 ; 38).

Data Dinas Kesehatan Kabupaten Grobogan Tahun 2015 angka kejadian penderita mencapai 11 kasus, termasuk data yang ada ditawangharjo yaitu ada 3 kasus, yang terdapat di Desa Jono. Pada pemberian obat pencegahan filariasis di desa Jono yaitu mencapai 682 jiwa kecuali anak dibawah 2 tahun, ibu hamil dan penderita penyakit berat.

Rumusan masalah penelitian ini yaitu Bagaiman Persepsi Ibu Tentang Pemberian Obat Filariasis Untuk Pencegahan Elephantiasis pada Balita di Desa Jono Kecamatan Tawangharjo Kabupaten Grobogan.

Tujuan penelitian ini untuk mengetahui persepsi ibu tentang pemberian obat filariasis untuk pencegahan elephantiasis pada balitadi Desa Jono Kecamatan Tawangharjo Kabupaten Grobogan. 


\section{Tinjauan Teoritis}

Filariasis atau penyakit kaki gajah adalah penyakit menular yang disebabkan oleh cacing filarial yang ditularkan melalui berbagai jenis nyamuk. Penyakit ini bersifat menaun (kronis) dan apabila tidak mendapatkan pengobatan akan mengakibatkan cacat menetap berupa pembesaran kaki, alat kelamin baik perempuan maupunn laki-laki (Padila, 2013: 411) Banyak species nyamuk yang berperan sebagai vektor filariasis, tergantung pada jenis cacing filarianya. Di Indonesia terdapat 23 species nyamuk yang diketahui bertindak sebagai vektor yaitu dari genus: Mansonia, Culex, Anopheles, Aedes dan Armigeres. Karena inilah filariasis dapat menular dengan sangat cepat. Secar rinci vektor nyamuk itu adalah : (Akhsin Zulkhoni, 2010 : 64 ).

1. Wuchereriabanchrofi perkotaan dengan vektor Culex quinquefasciatus.

2. Wunchereria banchrofi pedesaan dengan vektor Anopheles, Aedes dan Armigeres.

3. Brugia malayi dengan vektor Mansonia spp dan Anopheles barbirostris.

4. Brugia timori dengan vektor Anopheles barbirostris.

Pencegahan terhadap penyakit filariasis atau kaki gajah dapat dilakukan dengan jalan :

1. Berusaha menghindari diri dari gigitan nyamuk

2. Membersihkan air pada rawa-rawa yang merupakan tempat perindukan nyamuk.

3. Mengeringkan atau genangan air sebagai tempat perindukan nyamuk.

4. Membakar sisa-sisa sampah (berupa kertas dan plastik

5. Minimal melakukan penyemprotan sebulan sekali.

Pencegahan penyakit kaki gajah atau filariasis bagi penderita penyakit filariasis diharapkan untuk memeriksakan ke dokter agar mendapatkan penanganan obat-obatan sehingga tidak menyebabkan penularan kepada masyarakat lainnya. Perlu adanya pendidikan dan pencegahan serta pengenalan penyakit kaki gajah atau filarisis di wilayah masing-masing sangatlah penting untuk memutus mata rantai penularan penyakit ini. Membersihkan lingkungan sekitar adalah hal terpenting untuk mencegah terjadinya perkembangan nyamuk diwilayah tersebut (Padila, 2013 : 417-418). Sasaran POPM Filariasis ini dilaksanakan terhadap semua penduduk usia 2 tahun sampai dengan usia 70 tahun diseluruh wilayah Kabupaten / Kota endemis Filariasis dengan memberikan obat DEC dan albendazole secara missal bersamaan. Pemberian obat secara massal bersamaan ini dapat mematikan semua microfilaria yang ada di dalam darah setiap penduduk dalam waktu bersamaan, dan mencegah microfilaria (cacing filarial dewasa) menghasilkan microfilaria baru, sehingga rantai penularan filariasis terputus 
(Peraturan Menteri Kesehatan Republik Indonesia tentangPenanggulangan Filariasis2014:73)

\section{Metode Penelitian}

Metode penelitian yang digunakan adalah riset operasional kualitatif. Penelitian ini menggunakan pendekatan fenomenologis. Penelitian ini dipilih karena berusaha mendeskriptifkan data-data yang diperoleh berdasarkan ungkapan bahsa, cara berfikir, dan pandangan subyek yaitu pemberian obat filariasis untuk pencegahan elephantiasis. Teknik sampling yang digunakan adalah purposive sampling. Partisipan Ibu yang mempunyai anak balita 2-5 tahun yang diberi obat filariasis yang tinggal di Desa Jono. Triagulasinya yaitu Bidan desa yang mengelola desa yang mendapat pemberian obat untuk pencegahan filariasis. Tehnik pengumpulan data dengan menggunakan wawancara terarah (guide interview).Penelitian dilakukan bulan Desember 2015 sampai dengan Agustus 2016

\section{Hasil Penelitian}

1. Persepsi ibu tentang pemberian obat filariasis pada balita

a. Pendapat ibu tentang kaki gajah

Hasil penelitian didapatkan bahwa penyakit kaki gajah merupakan penyakit yang terjadi karena gigitan nyamuk yang disebabkan oleh nyamuk yang terinfeksi cacing filaria,didukung oleh triangulasi.

b. Penyebab penyakit kaki gajah

Hasil penelitian didapatkan bahwa penyebab dari penyakit kaki gajah yaitu karena nyamuk yang terinfeksi cacing filaria menghisap darah manusia atau menggigi tmanusia dan lingkungan yang kotor, jawaban ini dibenarkan oleh triangulasi sumber.

c. Cara penularan filariasis atau penyakit kaki gajah

Hasil penelitian didapatkan bahwa penularannya dari nyamuk yang terinfeksi cacing filaria yang kemudian menghisap darah orang, sesuai dengan yang dituturkn oleh partisipan, jawaban ini dibenarkan oleh triangulasi sumber.

2. Persepsi ibu tentang pencegahan filariasis pada balita

Hasil penelitian yang telah dilakukan didapatkan bahwa cara pencegahan filariasis atau kaki gajah yaitu dengan menjaga lingkungan bersih, membuang sampah pada tempatnya, tidak ada genangan air yang tidak terpakai, menghindari gigitan nyamuk serta melakukan penyemprotan nyamuk jika diperlukan. Jawaban ini dibenarkan oleh triangulasi sumber. 
3. Persepsi ibu tentang pemberian obat filariasis untuk pencegahan elephantiasis pada balita Berdasarkan penelitian yag didapatkan menunjukkan bahwa pemberian obat secara masal untuk pencegahan filariasis sangat membantu pada balita. Pernyataan ini dari partisispan mengenahi pemberian obat filariasis dibenarkan oleh triangulasi sumber.

\section{Pembahasan}

1. Persepsi ibu tentang pemberian obat filariasis pada balita Hasil penelitian maka didapatkan hasil bahwa 3 (tiga) ibu yang mempunyai anak balita mengemukakan tentang penyakit filariasis atau kaki gajah adalah penyakit yang disebabkan oleh cacing filaria yang ditularkan melalui nyamuk, serta penularannya yaitu dari nyamuk yang menggigit atau menghisap darah manusia.Menurut peneliti dari semua partisispan sudah mengetahui dan mengerti tentang filariasis atau kaki gajah karena sebelumnya telah diberikan penyuluhan tentang filariasis di daerah yang akan diberikan pengobatan masal serta mengetahuinya dari media seperti televisi.

Fiariasis merupakan penyakit yang ditularkan oleh serangga atau nyamuk yang telah terinfeksi cacing filarial yang merupakan penyakit menular menahun yang mengakibatkan cacat permanen berupa pembesaran pada kaki, lengan dan alat kelamin sehingga erlu diadakan pencegahan salah satunya dengan pemberian obat secara masaal baik bagi orang dewasa dan balita khususnya.

Hal ini sama dengan yang dituliskan oleh Akhsin Zulkhoni(2010 : 62) bahwa, Filariasis adalah suatu infeksi sistemik yang disebabkan oleh cacing filaria yang cacing dewasanya hidup dalam kelenjar limfe dan darah manusia, ditularkan oleh serangga (nyamuk), secara biologik penyakit ini bersifat menahun (kronis) dan bila tidak mendapat pengobatan akan menimbulkan cacat menetap berupa pembesaran kaki (kaki gajah) pembesaran lengan, payudara dan alat kelamin wanita ataupun laki-laki.Filariasis atau penyakit kaki gajah adalah penyakit menular yang disebabkan oleh cacing filarial yang ditularkan melalui berbagai jenis nyamuk. Penyakit ini bersifat menaun (kronis) dan apabila tidak mendapatkan pengobatan akan mengakibatkan cacat menetap berupa pembesaran kaki, alat kelamin baik perempuan maupun laki-laki (Padila, 2013: 411)

Filariasis merupakan penyakit yang membebani penderita baik secara fisik maupun mental.Beban fisik berupa cacat yang mengganggu penampilan dan mengganggu aktivitas fisik.Produktivitas menurun karena penderita sulit bergerak akibat pembesaran tungkai dan skrotum.Beban mental terjadi karena cacat fisik membuat penderita malu dan rendah 
diri, selain itu ada anggapan bahwa filariasis umumnya adalah penyakit kutukan dan penderitanya orang miskin, pendidikan rendah dan jauh daari fasilitas kesehatan.Oleh karena itu bantuan pemerintah untuk mengeleminasi filariasis ssangat diperlukan untuk mencegah terjdinya filariasis.

2. Persepsi ibu tentang pencegahan filariasis

Hasil penelitian didapatkan bahwa pencegahan filariasis atau kaki gajah merupakan hal yang biasa dilakukan yaitu seperti halnya menjaga lingkungan tetap bersih, menjaga kebersihan rumah, menutup jika ada genangan air dan yang paling penting sebisa mungkin menghindari gigitan nyamuk dan jika perlu dilakukan penyemprotan nyamuk disetiap rumah.Menurut pendapat peneliti untuk pencegahan filariasis telah dilakukan pada setiap keluarga dan semua partisipan mengetahui cara pencegahannya yaitu partisipan telah mendapatkan informasi atau penyuluhan dari tenaga kesehatan yang melakukan surveylens di daerah yang merupakan salah satu daerah yang mempunyai angka kejadian filariasis.

Pencegahan terhadap penyakit filariasis atau kaki gajah dapat dilakukan dengan jalan yaitu diantaranya berusaha menghindari diri dari gigitan nyamuk, membersihkan air pada rawa-rawa yang merupakan tempat perindukan nyamuk, mengeringkan atau genangan air sebagai tempat perindukan nyamuk, membakar sisa-sisa sampah (berupa kertas dan plastik) serta minimal melakukan penyemprotan sebulan sekali. Bagi penderita diharapkan untuk memeriksakan ke dokter agar mendapatkan penanganan obat-obatan sehingga tidak menyebabkan penularan kepada masyarakat lainnya. Pencegah penyakit filariasis, nyamuk penularannya diberantas merupakan cara yang paling efektif. Cara tepat untuk membrantas nyamuk adalah berantas jentik-jentiknya ditempat berkembang biaknya. Cara ini dinamakan dengan pemberantas sarang nyamuk filariasis, oleh karena tempat-tempat umum maka setiap keluarga harus bekerja sama dan berusaha melaksanakan pemberantasan sarang nyamuk filariasis (Depkes RI, 2011:7).Selain itu, pemberantasan sarang nyamuk bisa juga dilakukan melalui penggunaan insektisida. Cara penggunaan malation ialah dengan cara pengasapan (thermal fogging) atau dengan pengabutan (cold fogging). Ada juga insektisida yang bertujuan membunuh jentik-jentik nyamuk, yakni temphos (abate). Sedangkan cara yang tidak menggunakan abate adalah dengan 3M yakni menguras bak mandi, tempayan atau TPA minimal satu minggu sekali (Hendarwanto, 2011:422).

Seseorang dapat tertular Filariasis, apabila orang tersebut mendapat gigitan nyamuk yang mengandung larva infektif, proses ini biasa disebut sebagai rantai infeksi. Salah satu cara 
yang dapat digunakan untuk memutus rantai infeksi adalah dengan melakukan upaya pencegahan yang jug adapt menghilangkan atau mengurangii kemungkinan yang dapat meningkatkan potensi seseorang terkena Filariasis maka diperlukan upaya pencegahan.

3. Persepsi ibu tentang pemberian obat filariasis untuk pencegahan elephantiasis pada balita. Hasil penelitian didapatkan bahwa pemberian obat secara masal sangat membantu bagi semua penduduk yang berada di daerah Jono, baik dewasa (usia 70 tahun) serta khususnya pada balita (usia 2-5 tahun).Peraturan Menteri Kesehatan Republik Indonesia tentang Penanggulangan Filariasis (2014:73) yaitu : sasaran POPM Filariasis ini dilaksanakan terhadap semua penduduk usia 2 tahun sampai dengan usia 70 tahun diseluruh wilayah Kabupaten/Kota endemis Filariasis dengan memberikan obat DEC dan albendazole secara massal bersamaan. Pemberianobatsecara massal bersamaan ini dapat mematikan semua microfilaria yang ada di dalam darah setiap penduduk dalam waktu bersamaan, dan mencegah microfilaria(cacing filarial dewasa) menghasilkan microfilaria baru, sehingga rantai penularan filariasis terputus. Penggunaan doksisiklin dalam kurun waktu 4-6 minggu (menargetkan Wholbacia intraseluler) juga memiliki aktifitas macro filaricidal yang signifikan, seperti yang DEC/Albendazole digunakan setiap hari selama 7 hari.Penambahan DEC ke kursus pemberian 3 minggu doksisiklin baru-baru ini telah terbukti efektif dalam pengobatan filariasis limfatik.

\section{Kesimpulan}

1. Persepsi ibu tentang pemberian obat filariasis pada balita yaitu, pemberian obat secara masal sangat membantu, baik dewasa (usia 70tahun) serta khususnya pada balita (usia 2-5 tahun) pengobatan masal ini sangat membantu karena dalam hal akan mengakibatkan cacat permanen bagi penderita penyakit filariasis. Tidak hanya melakukan pencegahan secara awal untuk menghindari penyakit filariasis tetapi pengobatan secara dini juga sangat diperlukan agar tidak terjadi penyakit filariasis dan akan memutus mata rantai kejadian flariasis.

2. Persepsi ibu tentang pencegahan filariasis pada balita yaitu, pencegahan filariasis atau kaki gajah merupakan hal yang biasa dilakukan yaitu seperti halnya menjaga lingkungan tetap bersih, menjaga kebersihan rumah, menutup jika ada genangan air dan yang paling penting sebisa mungkin menghindari gigitan nyamuk dan jika perlu dilakukan penyemprotan nyamuk disetiap rumah. 


\section{Saran}

1. Bagi Puskesmas Tawangharjo

Diharapkan pihak puskesmas untuk meningkatkan sosialisasi tentang cara pencegahan filariasis dan memberikan pengobatan massal filariasis secara berkelanjutan untuk memutus rantai penyakit filariasis.

2. Bagi masyarakat

Diharapkan masyarakat khususnya ibu yang mempunyai anak balita (2-5 tahun) bisa menambah pengetahuan melalui sosialisasi yang diberikan oleh tenaga kesehatan di wilayah tersebut dan ikut berpartisipasi dalam program Pemberian Obat Secara Massal (POPM).

\section{Daftar Referensi}

Ambarwati, Eny Retna dan Y. Sriati Rismintari. 2011. Asuhan Kebidanan Komunitas. Yogyakarta : Nuha Medika

Dinas Provinsi Jawa Tengah. 2015. Profil Kesehatan Jawa tengan Tahun 2014. Semarang:

Dinas Provinsi Jawa Tengah

Harahap Marwali. 2008. Ilmu Penytakit Kulit. Jakarta : Hipokrates

Hendarwanto, 2011.Buku Ajar Ilmu Penyakit Dalam.Jakarta : FK.UI Jakarta

Mubaraq, Wahid Iqbal. 2012. Ilmu Kesehatan Masyarakat : Konsep dan Aplikasi dalam Kebidanan. Jakarta : Salemba Medika

Murwani Arita. 2009. Perawatan Pasien Penyakit Dalam. Yogyakarta : Mitra Cendikia Press

Notoatmojo, Soekidjo. 2011. Promosi Kesehatan. Jakarta: Rineka Cipta

Nola, 2015. Hubungan Sosio Demografi Dengan Kejadian Filariasis Di Kabupaten Pekalongan,. 59;66

Peraturan Menteri Kesehatan Republik Indonesia. 2014. Penanggulangan Filariasis. Jakarta:Peraturan Menteri Kesehatan Republik Indonesia

Purwandari, Atik. 2010. Ilmu Kesehatan Masyarakat dalam Konteks Kebidanan. Jakarta :EGC

Rizky, 2014. Analisis Faktor Risiko Kejadian Filariasis,. 1;12

Santoso, 2015. Faktor Risiko Filariasis di Jambi.,152;162

Willey Jhon. 2008. Filariasis(terjemahan).Ciba foundation symposium

Yohannie, 2015. Upaya Keluarga Dalam Pencegahan Primer Filariasis Di Desa Nanjung Kecamatan Margaasih Kabupaten Bandung.1;15 
Zulkhoni Akhsin. 2013. Parasitologi. Yogyakarta : Pustaka Rihama

Zahrotul, 2015. Cakupan POPM Filariasis di Kabupaten Sumba, 199;203

Zainul, 2015. Populasi Nyamuk Dewasa Di Daerah Endemis Filariasis Studi Di Desa Empat Kecamatan Simpang Empat Kabupaten Banjar,. 85-96 